\title{
Game and Narration. Identity Formation and Identity De-Construction
}

\author{
Rosa Gallelli ${ }^{1}$, Rossella Domenica Fanelli ${ }^{2}$ \\ University of Bari ${ }^{1}$, University of Foggia ${ }^{2}$, Italy
}

\begin{abstract}
The construction of reality, sexual identity, and social roles is mediated by media images. Video games have become agents in the development of identities in children. Video games affect the child's definition of gender, through gendered and sexual images. Video games portrayals of men and women are characteristically stereotypical: men are strong, aggressive, blunt and authoritarian; women are, even when they occupy the role of hero, subordinate to male characters or are presented in terms of their sexuality. Video games are an example of how technology has been designed for a particular gender. Girls were for a long time not taken into account in the design of videogames. The male or the masculine remains the invisible norm. Many of the most popular games are leading to increased gender stereotypicity. This is one of the reasons why the majority of the girls are non-players, while most of the boys are players. How video games may promote sexual health and reduce gender stereotypes?
\end{abstract}

\section{Introduction}

The premise for this paper is that health education in the field of sexuality has to be based on an analysis of what sexuality is and how it is defined in Western culture. This problematization is urged today as ever, from the current changes in the way we experience the body and the personal identity. This refers to the changes to which the sensory system is exposed by virtual reality, the dizzying acceleration of transports technologies, its propagation and the miniaturization of those communications, and refers also to the new freedom to constantly redesign their bodies through technologies of genetic engineering and the artificial and the new freedom to hire and live multiple selves, provisional, partial, contradictory and divided, as part of the infinite positioning and infinite knowledge and social connections are made possible in cyberspace.

Such an analysis first requires consideration of the issue of the mechanisms of "male", "female", "homosexual" and "transsexual" cultural productionreproduction, a re-evaluation of the topoi connected with sexual and gender differences and a critical reassessment of society's definitions of the concepts of difference. These are all essential to creating an environment in which an individual is able to freely develop his "self".
From this point of view, sex education is definable as promotion of gender creativity. The telos of the educational objectives is therefore not bound by legal or dogmatic considerations or influenced by the temptation to make the individual "conform" to certain identity models which are seen as "better" or "more desirable" than others. On the contrary, the educational aim is to support the individual in experimenting to discover where he/she "belongs" culturally by making his/her own choices about which path of personal identity to follow in order to gain fulfillment.

\section{Game and Gender Identity Construction}

Games of pretend - both in their traditional form and in their current electronic forms - constitute an extraordinary resource for the individual seeking to acquire a sense of sexual self, which is at the same time fluid, autonomous and creative. The games involve the forms of communication through which the individual, in the dialogue with himself/herself and with other players, takes on roles and enacts them. He/she is thus able to bring out, alongside his/her own ordinary self, those aspects of the self which are not expressed in everyday life, and to confront these constructively. A game thus enriches the process of definition of one's own identity, enabling the individual to reinterpret his/her own experience in the new narrative configurations of that game. In this way, play makes it possible above all to foster that important process through which each individual defines his/her own self in relation to the ongoing exploration of what that self may become.

Traditional and virtual games offer the same opportunities for expression: they provide a space, voice and body for the "Possible selves" that inhabit our imaginations. The importance of this kind of expression is already widely recognised in children, who - through games of pretend and games of disguise - are able to develop and improve both their ability to understand and to make use of symbolism, and their ability to try out and experiment with multiple identities, by constructing storylines which enable them to develop their perception of themselves as autonomous individuals.

Thus, games of pretend provide an excellent means of expression for a child's desires and creativity as well as laying the foundations for his/her ability to think in terms of symbols. 
On the other hand, however, as far as adults are concerned, there has from this point of view been a marked sense of embarrassment in our culture: the perception seems to be that the process of identity experimentation - considered essential for the child has to end with the onset of adulthood, which is seen as a culminating and defining moment in the development of the individual.

In Western culture, while competitive games and games of chance have acquired a certain status, games of pretend have been marginalised in the lives of both young people and adults. At the same time, the creative desire of these young people and adults to experiment with the multidimensional and evolving nature of their own identity has been covertly channelled in different directions: for the majority, in the direction of consumerism, where models and images are created on the basis of market interests; for the elite, in the direction of literary, cinematographic or theatrical production and consumption.

What the spread of virtual games is now doing is providing an undifferentiated supply - to young people, adults and children - of opportunities to enjoy the essence of play: to switch easily between many various identities in endless experiments that involve "crossing" the boundaries between roles, modes of feeling and being, and also between concepts, forms of knowledge, cognitive models and systems of values.

Videogames provide play activities with a new modus vivendi. The virtual nature of these new kinds of games brings about a significant change in the time-space framework thus enabling players to make their playing experience in spatial and temporal dimensions, which no longer coincide with a specific place and time. The disappearance of the main coordinates of the game gives access to a subjectivity that is not bound to the spatial context and that is free to adopt and experience manifold Selves, which can be temporary, partial, contradictory and divided, within the various positionings and the social and cognitive connections provided by the virtual reality. What is today the role of videogames in the process of gender identity building? How can the educational function of videogames be reshaped to counter gender-based clichés, stereotypes and prejudices?

\section{Games and Videogames between Old and News Narrations}

Games, regardless of the kind of means they use be it a toy, an electronic system, fantasy, creativity whether they imply climbing a tree or moving to the next level of a videogame, are always an important tool for experience, education and identity building.
Games are symbolic places where children, beside acquiring knowledge on the world, accomplish important processes of self-identity building.

To this regard, the narrative dimension of both the symbolic thought and the virtual game deserves particular attention, since such dimension fully coincides with the narrative dimension of identity building processes.

The narrative is a kind of thought insofar as, whilst the logical thought is specialized in "dealing with physical 'things'", the narrative thought is specifically dedicated to "dealing with people and their conditions".

It is always an individual thought, which moves within the reality offering a partial reconstruction of it because it is closely linked to the point of view (in cognitive and emotional, historical and social, cultural and motivational terms) of the subject that puts it forward.

Moreover the narrative dimension is also a "tool of the mind able to create meanings", since it helps people to understand the meaning of the experiences they (directly or indirectly) go through or simply witness.

Each narrative is therefore a thought structure used to order reality, which for its own nature is fragmented and unpredictable: in the narrative continuum, a dynamic and complex reality, where actions, objectives, purposes, expectations and coincidences are interrelated at different levels and often chaotically, can be organised as a series of events that are closely intertwined within a particular frame and that are related to definite actors and causes in a broader context of situations which, according to specific processes, move towards a given direction and future.

As a consequence, the narrative thought reveals its relational nature, through which a harmonious relation is established between the author's and the receiver's points of view, thus contributing to a successful communication.

Individuals perceive themselves as "identities", when they manage to arrange the temporal dimension of their existence in a narrative structure. The Self can be recognized only if events, images and situations are organised in a coherent narrative discourse. This discourse can never be considered finished once and for all, but it is always open to new definitions, as it is constantly exposed to the imaginative inputs deriving from the environment.

Hence if we assume that the unique nature of the Self is always the temporary result of the way individuals every time reconstruct and interpret their actual existence and if we assume that, as briefly explained above, the identity has a primarily relational and narrative nature, which permeates the constant dialogue that the individual establishes with the others as well as the dialogue between the different "positionings" held simultaneously by an 
individual at a given time, we can conclude that it is the very cohesive force of the narrative that probably gives us the chance to represent coherently the development and the evolution of the different temporary "positionings" and dialogues composing the individual existence.

\section{Fluidity in Education. The "Meta- Play” Educational Laboratory}

As far gender is concerned, it would appear that fluidity is now and will continue to be an established phenomenon. In fact, as social and cultural complexity increase as a result of the dynamism engendered by globalism and the advance of technology, we find ourselves increasingly called upon to confront the issue of gender difference. In a way, the ordinary circumstances of our private and public lives increase the opportunities to question and negotiate with others the "male"/"female" dichotomy, and the relevant stereotypes. To take an obvious example: on a day-today basis, does a woman manager not find herself adopting "male" traits and behaviour? And does a male health worker, on the other hand, not end up adopting "female" traits and behaviour? By the same token, is it really possible for an ordinary heterosexual couple to avoid some kind of interchanging of the emotive, cognitive and behavioural roles and prerogatives that have been traditionally defined as "male" and "female"? Moreover, the "normal" heterosexual two-gender division is no longer the only way of experiencing sexuality: valid alternative interpretations, while still relatively rare, are increasing dramatically.

Nonetheless, this intensification of the production and diffusion of models, ideas and images with which to identify, is not automatically accompanied by an improvement in the ability to take a critical and creative approach to the encounter-contrast between differences. It is in fact increasingly difficult for an individual to disentangle his/her own attempts to construct and reconstruct an identity from the pressure to conform in a consumerist, pleasureseeking society. There is even an increased risk that this symbolic pressure, disguising itself as one of the numerous existential possibilities on offer, may be so subtly concealed as to be almost unrecognisable.

The games and toys currently on offer reflect and reinforce the cultural set-up, and provide real world opportunities for children, adolescents and adults to experience the pleasure of experimenting with their own multiple selves, without, however, allowing for proper critical control or imaginary transposition.

In the processes of play which enable the individual to experience fluidity of gender identity, critical control and imaginary transposition require a series of specific abilities:
- an ability to recognise the various aspects of the self brought into play through the roles one acts out;

- an ability to keep open the lines of communication between the different aspects of the self: those which are operational in normal life, those hitherto never brought into operation and those which can only be made operational through the profound transformations which play makes possible;

- an ability to recognise the evolution and transformation of one's own approaches to play, of the chosen "play worlds" and of the roles played;

- an ability to recognise one's selves as "incomplete" and constantly "changing", open to the idea of encountering and being seduced and hybridised by existential possibilities other than those ordinarily experimented with;

- an ability to identify and discuss the cultural models underlying the games in which one takes part, as well as the connections between these models and one's own play preferences.

\section{The "Meta-Play" Educational Laboratory: an Example}

Videogames can contribute to the educational and human development of individuals, if they are used as a tool within an education aimed at enhancing fluidity, an education that makes fun of identities and that plays with identities.

Videogames are an important way to make syncretic, kinesthetic and synesthetic experience and, as a consequence, they enable players to explore, manipulate, manage, discover and learn. They are real "learning machines".

Videogames - seen as form of edutainment- are not only fundamental tools for identity building, but they also have a great educational potential. They spur players to choose different ways to solve a problem, according to their knowledge and skills; moreover they allow the acquisition of expertise through the repeated exercise of specific skills necessary to solve increasingly complex problems; finally they foster new cooperative models of knowledge building, namely the development of "individuals able to think and act independently and at the same time characterised by a deeply rooted ability to work in team and in an international and intercultural environment.

How video games may promote sexual health and reduce gender stereotypes?

We examined group differences in gender representation, sexual health and sexual identity for groups defined by gender and video-game playing experience. We used a social impact video game 
designed to promote sexual health and sexual education.

The experimental group (15-17 years old) was trained using a social impact video game. The control group (15-17 years old) played a non-social impact video game. We used a questionnaire to assess the knowledge level of sexual health and sexual transmitted diseases, and the influence of the videogames images on gender representation and sexual identity construction.

The major goal of this study is to demonstrate that a social impact video game may improve the gender representation and its implications for the sexual health and sexual identity.

The control group played a non-social impact video game: GTA - San Andreas.

We asked:

"Do you Know the game GTA - San Andreas?”: $100 \%$ answered Yes;

"Have you ever played it?”: 80\% answered Yes; 20\% answered No;

During the play session we register their conversations, they said:

"Kill him!", rather than after have had sexual relationships with a prostitute "Kills her therefore steals the money!"

We made a "GTA - San Andreas Deconstruction" through:

- $\quad$ Storytelling in first person of the male and the female character in order taking conscience of the roles;

- $\quad$ Discussion on stereotyped characters;

We than administer the Personal Attributes Questionnaire (Spence, Helmreich, \& Stapp, 1974), used to determine the sex-typing of personality, to assess the subjects' sense of characters.

As to female character's aggressiveness (from 1 not at all aggressive - to 5 very aggressive) they answered:

$$
\begin{array}{lll}
\text { - } & 54 \% & \text { answered 1 } \\
\text { - } & 17 \% & \text { answered 2 } \\
\text { - } & 17 \% & \text { answered 3 } \\
& & \\
\text { - } & 12 \% & \text { answered 4 } \\
\text { - } & 0 \% & \text { answered 5 }
\end{array}
$$

As to male character's aggressiveness (from 1 not at all aggressive - to 5 very aggressive) they answered:

$$
\begin{array}{lll}
\text { - } & 0 \% & \text { answered 1 } \\
\text { - } & 0 \% & \text { answered 2 } \\
\text { - } & 0 \% & \text { answered 3 } \\
\text { - } & 12 \% & \text { answered 4 } \\
\text { - } & 88 \% & \text { answered 5 }
\end{array}
$$

As to female character's independence (from 1 not at all independent - to 5 very independent) they answered:

$$
\begin{array}{lll}
- & 21 \% & \text { answered 1 } \\
- & 12 \% & \text { answered 2 } \\
- & 33 \% & \text { answered 3 }
\end{array}
$$

$$
\begin{array}{lll}
- & 21 \% & \text { answered } 4 \\
\text { - } & 12 \% & \text { answered } 5
\end{array}
$$

As to male character's independence (from 1 not at all independent - to 5 very independent) they answered:

$\begin{array}{lll}\text { - } & 16 \% & \text { answered 1 } \\ \text { - } & 7 \% & \text { answered 2 } \\ \text { - } & 25 \% & \text { answered 3 } \\ \text { - } & 12 \% & \text { answered 4 } \\ \text { - } & 50 \% & \text { answered } 5\end{array}$

As to female character's submission (from 1 very submissive - to 5 very dominant) they answered:

- $\quad 71 \%$ answered 1

- $12 \%$ answered 2

- $\quad 17 \%$ answered 3

- $\quad 0 \% \quad$ answered 4

- $\quad 0 \% \quad$ answered 5

As to male character's submission (from 1 very submissive - to 5 very dominant) they answered:

- $\quad 0 \% \quad$ answered 1

- $\quad 0 \% \quad$ answered 2

- $\quad 29 \%$ answered 3

- $\quad 25 \%$ answered 4

- $\quad 46 \%$ answered 5

As to female character's inferiority (from 1 feels very inferior - to 5 feels superior) they answered:

$\begin{array}{lll}- & 29 \% & \text { answered 1 } \\ - & 25 \% & \text { answered 2 } \\ - & 46 \% & \text { answered 3 } \\ \text { - } & 0 \% & \text { answered 4 } \\ \text { - } & 0 \% & \text { answered } 5\end{array}$

As to male character's inferiority (from 1 feels very inferior - to 5 feels superior) they answered:

$\begin{array}{lll}- & 0 \% & \text { answered 1 } \\ \text { - } & 0 \% & \text { answered 2 } \\ \text { - } & 16 \% & \text { answered 3 } \\ \text { - } & 25 \% & \text { answered 4 } \\ \text { - } & 59 \% & \text { answered } 5\end{array}$

The control group perceive GTA - San Andreas' female character as: not aggressive, not independent, submissive and inferior. Conversely the control group perceive GTA - San Andreas' male character as: aggressive, independent, dominant and superior.

After the laboratory the control group get a sense of the stereotypes perpetrate by this videogame.

The experimental group was trained using a social impact video game on sexual health and sexual transmitted diseases.

We used a questionnaire to assess the knowledge level of sexual health and sexual transmitted diseases. Before the laboratory we asked them:

"The following which of diseases are transmitted through the sexual relationships?"

$\begin{array}{lll}- & 12 \% & \text { Mediterranean Anemia } \\ - & 24 \% & \text { Hepatitis turns } \\ - & 32 \% & \text { Syphilis } \\ - & 88 \% & \text { Gonorrhoea } \\ - & 88 \% & \text { AIDS } \\ \text { - } & 24 \% & \text { Some Tumors }\end{array}$




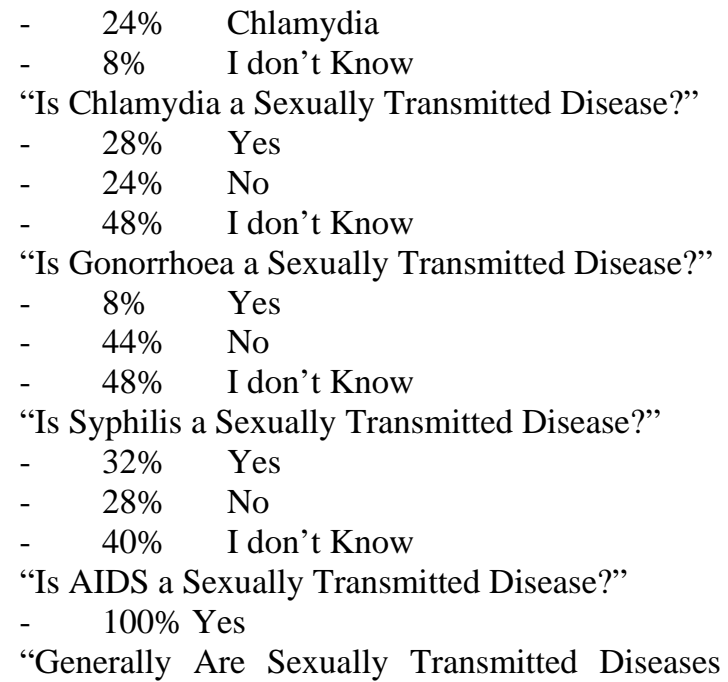
Asymptomatics?”

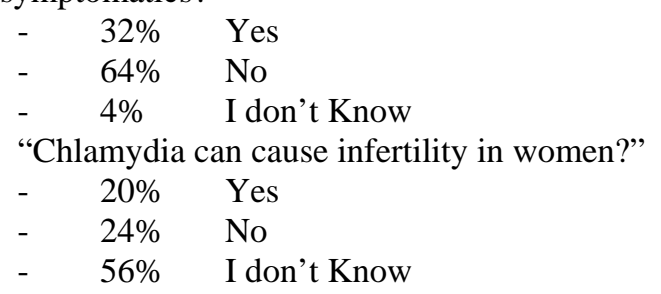

After the laboratory we asked them the same questions to assess if they acquired information about sexual health and sexual transmitted diseases:

"The following which of diseases are transmitted through the sexual relationships?”

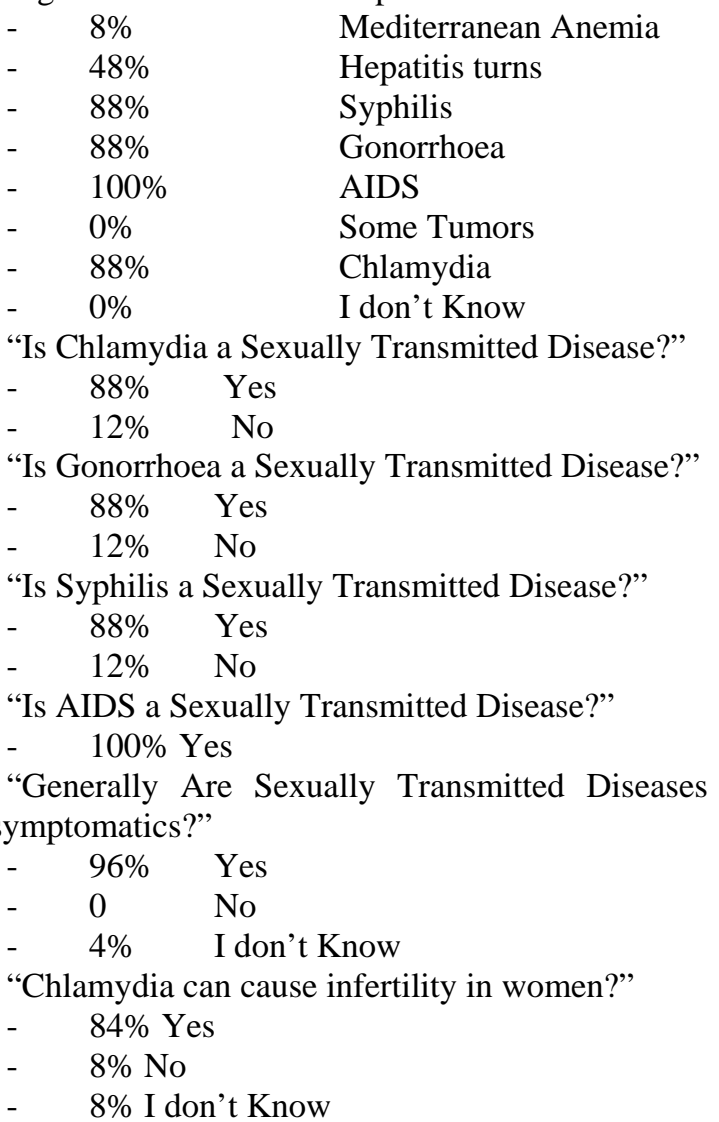

So the game of pretend and videogames develops not only the ability to de-contextualise, "mentalise", decentralise, integrate, and exert executive control, but also reflective skills.

The objective then, for those concerned with planning education, is to create paths of development - which obviously differ in nature depending on whether they are designed for children, adolescents or adults - in which play experiences are accompanied by meta-play experiences.

\section{References}

[1] Balzotti A., Gallelli R., Todarello O., Gioco e costruzione della mente, Franco Angeli, Milano 2008.

[2] Butler J., Undoing Gender, Routledge, London, 2004.

[3] Cassell J., Jenkins H., From Barbie to Mortal Kombat: Gender and computer games, The MIT Press, Cambridge, MA, 1998.

[4] Gallelli R., La scuola tra individualizzazione e collaborazione, Editori Riuniti, Roma 2007.

[5] I. D. Cherney, K.London, K. Glover, R. A. Gill and B. O. Ryalls, "The Effects of Stereotyped Toys and Gender on Play Assessment in Children Aged 18-47 Months”, Educational Psychology, 2003, 23:1, pp. 95-106.

[6] I.D. Cherney, K.London, "Gender-linked differences in the toys, television shows, computer games, and outdoor activities of 5- to 13-year-old children”, Sex Roles, 2006, Volume 54 Issue 9, pp. 717 - 726.

[7] Kafai Y. B., Heeter C., Denner J., Sun J. Y., Beyond Barbie ${ }^{\circledR}$ and Mortal Kombat: New Perspectives on Gender and Gaming, The MIT Press, Cambridge MA, 2008.

[8] Stone A. R., The war of desire and technology at the close of the mechanical age, MIT Press Cambridge, MA, USA, 1995.

[9] Spence, J. T., Helmreich, R., \& Stapp, J., "The Personal Attributes Questionnaire: A measure of sex role stereotypes and masculinity-femininity.”, JSAS Catalogue of Selected Document in Psychology, 1974, 4, pp. 43-44.

[10] Markus H. R., Nurius P., "Possible selves", American Psycologist, 1986, vol. 41, no. 9, pp. 954-969 